\title{
Validation of the least squares fitting method (Isf) during nava and psv ventilation
}

\author{
F Dalla Corte ${ }^{1 *}$, S Spadaro ${ }^{1}$, S Grasso ${ }^{2}$, V Cricca ${ }^{1}$, G Biondi ${ }^{1}$, A Fogagnolo ${ }^{1}$, G Valpiani ${ }^{1}$, R Di Mussi ${ }^{2}$, S Bertacchini ${ }^{1}$, \\ MV Colamussi ${ }^{1}$, E Marangoni ${ }^{1}$, CA Volta $^{1}$
}

From ESICM LIVES 2015

Berlin, Germany. 3-7 October 2015

\section{Introduction}

The Least Squares Fitting (LSF) is a computerized method of analysis of respiratory system mechanics. It is based on applying a regression analysis for every sample points of the loop of pressure, flow and volume by fitting the equation $\mathbf{P}_{\mathbf{a w}}=\mathbf{R}_{\mathbf{r s}} \times \mathbf{V}^{\prime}+\mathbf{V}_{\mathrm{T}} / \mathbf{C}_{\mathbf{r s}}+\mathbf{P E E P} \mathbf{P}_{\text {tot }}$ during inspiration [1]. This technique has been already validated in Controlled Mechanical Ventilation (CMV) and at high level of Pressure Support Ventilation (PSV) [2]. However this method gives unreliable values of resistance $\left(R_{r s}\right)$ and elastance $\left(E_{\mathrm{rs}}\right)$ in presence of inspiratory muscle activity and in absence of an adequate neuromuscular coupling. We reasoned that NAVA (Neurally-Adjusted Ventilatory Assist) ventilation should assure a better neuromuscular coupling compared to PSV and hence the coefficient of determination (CD) of the above equation should be much higher during NAVA ventilation.

\section{Objectives}

The aim of this study was to prove the efficacy of the LSF method in obtaining reliable respiratory mechanics data in two different ventilatory modes.

\section{Methods}

Twelve patients with acute respiratory failure were enrolled at the admission to the ICU and ventilated using in random order either PSV or NAVA for 3 hours with the same Positive End Expiratory Pressure (PEEPe) and tidal volume (VT) settings. Flow and pressure traces were recorded and subsequently analyzed using the LSF method

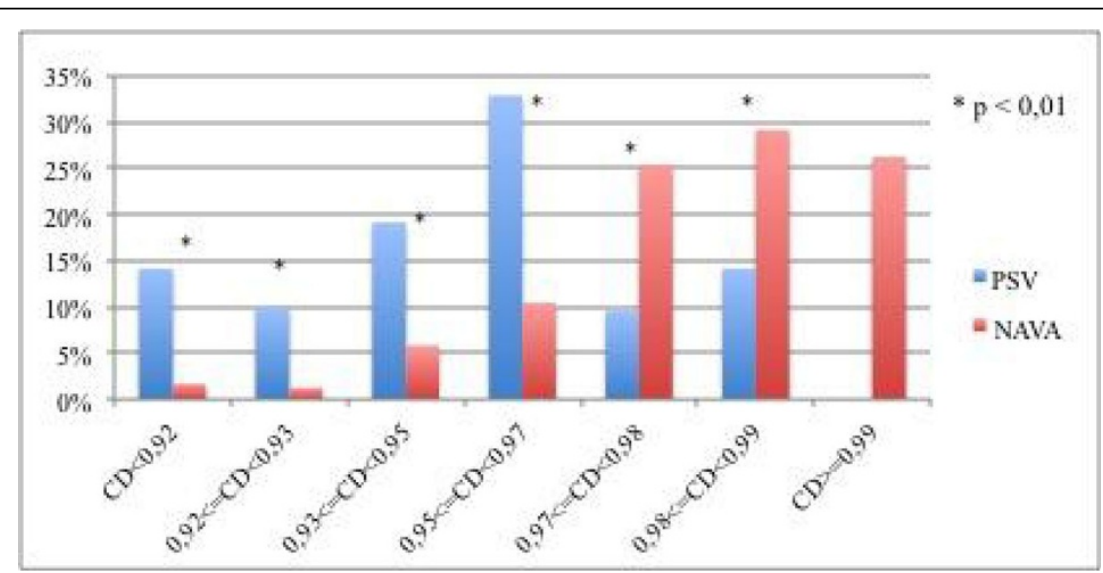

Figure 1

${ }^{1}$ University of Ferrara, Morphology, Surgery and Experimental Medicine,

Ferrara, Italy

Full list of author information is available at the end of the article

(c) 2015 Dalla Corte et al.; This is an Open Access article distributed under the terms of the Creative Commons Attribution License (http://creativecommons.org/licenses/by/4.0), which permits unrestricted use, distribution, and reproduction in any medium, provided the original work is properly cited. 


\begin{tabular}{|c|c|c|c|}
\multicolumn{2}{|c|}{} & $\begin{array}{c}\text { PSV_Elastance } \\
\text { (cmH20/I) }\end{array}$ & $\begin{array}{c}\text { NAVA_Elastance } \\
\text { (cmH20/I) }\end{array}$ \\
\hline \multirow{2}{*}{$\mathrm{CD}<0,95$} & MEDIAN & 29,1 & 28,7 \\
& IQR & 0,2 & 1,4 \\
\hline \multirow{2}{*}{$0,95<=C D<0,97$} & MEDIAN & 29,2 & 29,4 \\
\cline { 2 - 2 } & IQR & 1,4 & 2,0 \\
\hline \multirow{2}{*}{$\mathrm{CD}>=0,97$} & MEDIAN & 29,1 & 29,2 \\
\cline { 2 - 2 } & IQR & 1,5 & 3,6 \\
\hline
\end{tabular}

Figure 2

to obtain data of Rrs, Ers, PEEPtot and coefficient of determination (CD). NAVA and PSV were first compared in terms of $\mathrm{CD}$ during the 3 hours of recording. Furthermore, we selected 100 consecutive breaths for each patient in each ventilatory mode to compare the values of elastance (the only non-flow dependent of the equation of motion) obtained either in NAVA or PSV.

\section{Results}

The CD during NAVA ventilation was statistically higher than that obtained during PSV (Figure 1) (Chi-squared test: $\mathrm{p}<0.001)$. CD intervals are based on the percentiles of $C D$ distribution in the two ventilatory modes. $E_{r s}$ values for PSV and NAVA are presented in Figure 2.

\section{Conclusions}

Our results seem to confirm that the neuromuscular coupling is much better preserved during NAVA than during PSV.

\section{Authors' details}

${ }^{1}$ University of Ferrara, Morphology, Surgery and Experimental Medicine, Ferrara, Italy. ${ }^{2}$ University of Bari, Emergency and Organ Transplantations, Bari, Italy.

Published: 1 October 2015

\section{References}

1. Volta CA, Marangoni $E$, Alvisi $R$, et al: Respiratory mechanics by least squares fitting in mechanically ventilated patients: application on flowlimited COPD patients. Intensive Care Med 2002, 28:48-52.

2. Iotti GA, Braschi A, Brunner JX, et al: Respiratory mechanics by least square fitting in mechanically ventilated patients: applications during paralysis and during pressure support ventilation. Intensive Care Med 1995, 21:406-413.

\section{Submit your manuscript to a SpringerOpen ${ }^{\circ}$ journal and benefit from:}

- Convenient online submission

- Rigorous peer review

- Immediate publication on acceptance

- Open access: articles freely available online

- High visibility within the field

- Retaining the copyright to your article

Submit your next manuscript at $>$ springeropen.com 